\title{
Perceived career management challenges of academics at a South African university
}

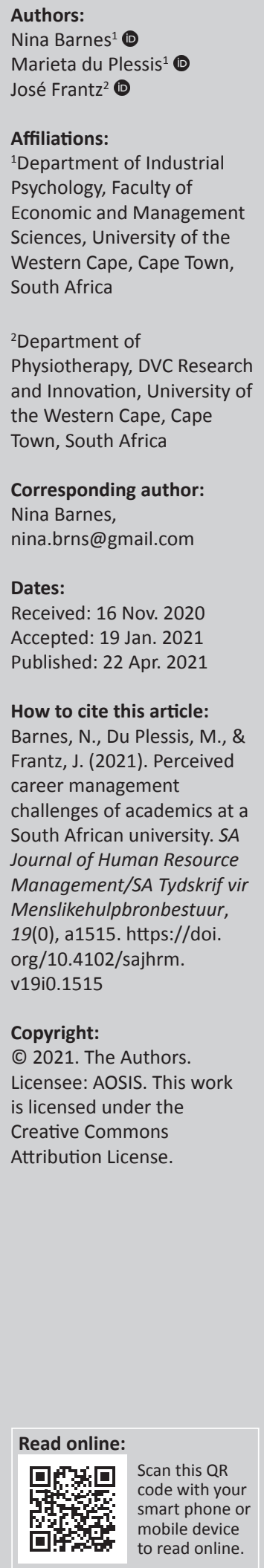

Orientation: Understanding academic career challenges is important at a national and global level, to support academic career progression. Whilst challenges are identified in academic career literature, higher education institutions are identified as complex interdependent structures and, therefore, encouraged to be studied from a perspective of interdependency and complexity.

Research purpose: To explore and describe the perceived career management challenges of academics at a South African university.

Motivation for the study: To address the need for an integrated approach, from an individual and organisational perspective, through a systems-thinking framework (STF), which acknowledges academic career progression as an interdependent and complex system.

Research approach/design and method: A qualitative, phenomenological approach, through individual semi-structured interviews with 17 academics, across all career phases.

Main findings: The study confirmed typical challenges captured in literature, and identified a number of additional challenges, through a systems thinking approach, as perceived by academics in all career phases. Challenges were identified at individual, departmental, organisational and societal levels. Personality; holistic well-being; team dynamic; institutional culture; role transition; institutional strategies, policies, systems and support, interpersonal/ peer support; social culture in which university is located; regulatory bodies; and external stakeholders are new contributions to the existing literature/knowledge.

Contribution/value-add: An understanding of career management challenges, as perceived by academics, for the purpose of strategy development. In addition, - to provide leaders and talent management practitioners in the higher education sector with the components to consider, through a systems thinking approach, when reproducing contextually sensitive maps and negotiating the landscape for academic career success.

Keywords: career management; academic career challenges; higher education; systemsthinking framework; career development.

\section{Introduction}

Understanding the challenges associated with the academic profession is globally acknowledged by universities as critical for the strategic management of academic careers, as well as for institutional success (Szelągowska-Rudzka, 2018). In addition, the description of career challenges in South Africa is essential to inform and direct the career management and progression of academics and to address national priorities, as set against the National Development Plan 2030 (Republic of South Africa [RSA], National Planning Commission [NPC], 2013, p. 319). Therefore, it is important to study the academic career path in its own right, because academia is a large, influential sector in any society, whilst it enjoys a continued expansion (Zacher, Rudolph, Todorovic, \& Ammann, 2019).

The academic career includes a unique career path. The roots of the academic career can be traced back to Socrates and Plato, and their ideas of academia, as a source of wisdom (Baruch \& Hall, 2004). Caplow and McGee (2001), conceivably, were the first to examine the academic career, focussing on academia as a social phenomenon. However, the term, academic career, opens a diverse and complex world that defies easy definition or categorisation (Strike \& Taylor, 2009). Pithouse-Morgan, Naiker, Pillay, Masinga and Hlao (2016) argue that being an academic as well as what constitutes academic work and the meanings associated with becoming an academic are contested and constantly changing. Literature indicates that there is an agreed view that academia, undoubtedly, has changed over time (Callaghan, 2015). A national review, conducted by the Council on Higher Education (CHE, 2016, p. 10), reports on such changes, whilst highlighting their impact on institutional 
structures, as well as the size and shape of systems, in the curriculum, in pedagogy, in modes of delivery, in research and in the relationship of institutions with external communities. However, academic career progression is still dependent on key milestones, challenges and tensions, which need to be managed successfully, to progress along the academic career path (Zacher et al., 2019).

With the given context in mind, challenges associated with academic career management are identified, in academic career literature (Pienaar \& Bester, 2007). Studies distinctly highlight work overload (Monnapula-Mapesela, 2002), role conflict (Miller, 2003), poor remuneration (Koen, 2006), inadequate performance management (Miller, 2003), insufficient support for teaching and research (Nelson \& Burke, 2000), discrimination in terms of race and gender (Tytherleigh, Rothmann, \& Barkhuizen, 2008), lack of transparency (Tytherleigh et al., 2008) and poor communication (Ball, 2004), as the typical career management challenges of academics. However, a recent review confirms the lack of an integrated career management approach from an individual and organisational perspective (Zacher et al., 2019). Maguad (2018) argues that the effectiveness of an improvement initiative should not be addressed in isolation, as the elements of the higher education system, like any other organisation, are interrelated and interdependent. This argument emphasises the importance of managing careers in an organisation as an actual system, which requires key consideration for contextual factors (Baruch \& Peiperl, 2000). Therefore, understanding the challenges in the higher education system, as well as the context in which it operates, is important to ensure the effective management of academic careers (Szelągowska-Rudzka, 2018). In addition, higher education institutions are complex interdependent structures and consequently should be studied from the perspective of complexity, and methods that consider this complexity should be applied (Korsakova, 2019). Ragin (2000) referred to this complexity as multiple conjuncture causation. This implies that, most often, it is a combination of conditions that produces a phenomenon; specifically, several different combinations of conditions may produce the same outcome, and depending on the context a given condition may very well have a different impact on the outcome.

A systems thinking approach to career development, therefore, recognises career management as a 'complex of elements standing in interaction' (Von Bertalanffy, 1967, p. 133), and 'single parts and processes cannot provide a complete picture of the vital phenomena' (Von Bertalanffy, 1967, p. 133). The approach further provides a systemsthinking framework (STF), as adopted in this study, which is underpinned by a meta-theoretical perspective of influences, relevant to an individual's career development, by showing the many complex and interrelated systems, in which career development occurs (McMahon \& Patton, 2018).

\section{Research purpose}

The systems-thinking approach is in line with the argument that not all higher educational institutions can respond in an identical way; therefore, institutions should design their own future, as well as the best manner in which to adjust and adapt to their individual context (Waller, Lemoine, Mense, Garretson, \& Richardson, 2019). Although literature on the typical career obstacles that academics in higher education institutions experience distinctly exists (Pienaar \& Bester, 2007), institutions are encouraged to consider an integrated approach, from an organisational perspective of complexity, whilst considering institutional context (De Vos \& Cambré, 2017). This current research, therefore, was aimed at exploring and describing the perceived career management challenges of academics at a South African university. The contextual challenges of the academics are acknowledged and could further inform the career management strategies of academics.

\section{Literature review}

\section{Career management}

To understand the concept of career management and its associated challenges, it is necessary to consider the term, career. There are two approaches to viewing a career (Greenhaus, Callanan, \& Godshalk, 2010). In the one approach, a career is viewed as a structural property of an occupation or an organisation, whilst in the other approach it is viewed as a property of an individual, rather than an occupation or an organisation. Therefore, a career is viewed as more than work performance and includes a pattern of work-related experiences that span the course of a person's life (Greenhaus et al., 2010). Amongst the classic descriptions, Super's definition, in 1976, describes career as the course of events that constitute a person's life, the sequence of occupations and other life roles, which combine to express an individual's commitment to work in his or her total pattern of self-development (Patton \& McMahon, 2014, p. 4).

These definitions proclaim that careers are dynamic and unfold throughout life, whilst it is unique to each person and dependent on individual choices. In addition, career management is defined through an individual perspective and an organisational perspective. From an organisational perspective, career management is concerned with the intervention, namely strategies and practices that plan and shape the development and progression of employees, in accordance with the organisation's talent management needs, ensuring a talent flow to create and maintain the required talent pool (Guan, Zhou, Ye, Jiang, \& Zhou, 2015).

From an individual perspective, career management is defined as a process by which individuals develop, implement and monitor their career goals and strategies (Greenhaus et al., 2010). Whilst career management and career development are generally incorporated as interchangeable constructs, career development, which is more commonly referred to as career progression, in the higher education context is an on-going process, through which an individual progresses through a series of stages, each characterised by a relatively unique set of issues, themes and challenges (Schreuder \& Coetzee, 2016). Although career literature helps to substantiate the responsibilities, benefits and implications for the organisation, as well as the individual, respectively (Segers \& Inceoglu, 
2012), limited research exists, from an organisational perspective, to include a broader consideration and approach, namely the individual, as well as the organisation, within the broader societal context in which it operates (De Vos \& Cambré, 2017). Literature, therefore, supports the view that an integrated career management approach should be considered, from an individual and organisational perspective of complexity, whilst considering organisational context.

Career management is underpinned by career development theory that indicates a relatively short, yet significant history (Baruch, Szücs, \& Gunz, 2015). The major career development theories could be categorised broadly to include personenvironment fit theories, life-span theories, cognitivebehavioural theories, psychodynamic approaches, situational or sociological and social cognitive theories (Gothard, Mignot, Offer, \& Ruff, 2001). Career development theories have to be viewed within the context of the time in which they were developed and that the theories were in response to the prevalent social concerns at the time (Watts, Hawthorn, Law, Killeen, \& Kidd, 1996).

Whilst research on career development theories has led to refined career propositions and strategies, the field seems to remain subject to much criticism. The criticism includes inadequate as well as incomplete theory that lacks comprehensiveness and coherence (Patton \& McMahon, 2014). More specifically, career development theory is critiqued for its failure to account for diverse populations and social justice (Blustein, 2013), with a key focus on individual issues, to the detriment of contextual issues (Leong \& Hartung, 2000).

In addition, career theory has been criticised for being segmented within the individual theoretical models (Patton \& McMahon, 2014). However, career development theory in the 21st century continues to respond to challenges in three main areas, namely the need for integration or convergence of theories, the importance of integrating related disciplines into the field and the increasing influence of constructivism and social constructivism (McMahon \& Patton, 2018). It is against this background that the researchers in this study adopted an STF, to provide a meta-theoretical framework for the integration of career development theories, by using systems theory.

\section{A systems-thinking framework (STF)}

The STF is a holistic meta-theoretical framework that accommodates the content influences as well as the process influences on individual career development (McMahon \& Watson, 2008). It identifies several key interrelated systems, including the intrapersonal system of the individual, the social system and the environmental-societal system, as illustrated in Figure 1.

The individual system is composed of several intrapersonal content influences, which include demographics, individual characteristics, interests and abilities. Influences that represent the content of the social system include the immediate environment and community, whilst environmental-societal system influences include broader structural and systemic context. Whilst the influences in the environmental-societal system may seem less directly related to the individual, the impact is profound on career development (Patton \& McMahon, 1999).

The process of influence is acknowledged within, as well as between, these systems. Patton and McMahon (1999) used the term recursiveness to describe this process of influence, which refers to the interaction, the multi-directionality of influence, as well as the relationship between all the systems, bearing in mind that the individual system, along with the contextual subsystems, are open systems and consequently permeable to influence. Recursiveness is a central construct of the STF and emphasises the inseparability of the parts from the whole; therefore, it is essential to think of career management as an integrated and dynamic process (Vondracek, Ford, \& Porfeli, 2014). In addition, career management challenges are set within the context of past, present and future (Patton \& McMahon, 1999).

Based on the literature reviewed here, the researchers in this study aimed to address the following research question, 'What are the career management challenges of academics at individual and organisational levels'?

\section{Research design Research approach}

The study was underpinned by a constructivist worldview, which holds knowledge as multiple or relative truths, as individuals seek understanding of the world in which they live (Creswell, 2014). The approach embodied a qualitative, phenomenological study that included in-depth, rich, detailed and heavily contextualised descriptions of academic experiences, which further allowed the researchers to identify and extract themes, as well as integrate these themes into meaningful descriptions (Munhall, 2001).

\section{Research method}

\section{Research setting}

The study was conducted at a public university in the (location masked for blind review), South Africa. Historically, the institution has been classified as a previously disadvantaged institution, and has been the vanguard of South Africa's historic change, with a distinctive academic role in helping to build an equitable and dynamic nation. The university is challenged to demonstrate that it is capable of competing with the best, as well as play a prominent role in the intellectual, social and economic life of the nation. Seven academic faculties are hosted by the institution, including Faculties of Arts and Humanities, Community and Health Sciences, Dentistry, Education, Economic and Management Sciences and Law (2013).

\section{Entrée and establishing researcher roles}

Following the permission granted by the university to conduct this research, the researchers discussed the planning and preparation of the data collection process. The first author took on the role of interviewer, whilst the remaining 


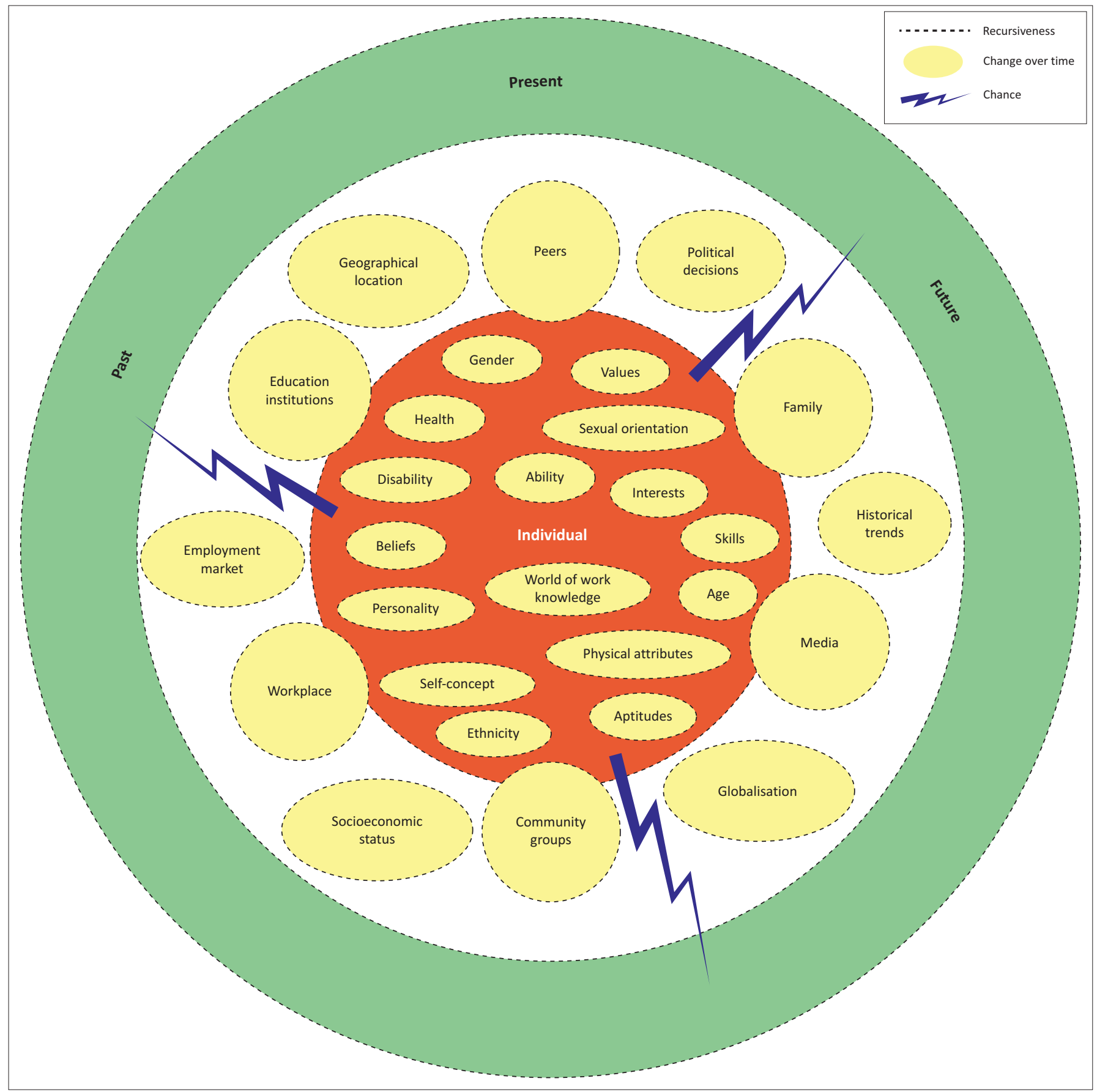

Source: Patton, W., \& McMahon, M. (1999). Career development and systems theory: A new relationship. Washington, DC: Thomson Brooks/Cole Publishing Co.

FIGURE 1: A systems-thinking framework that includes several interrelated systems to consider for individual career development.

authors were consulted as experienced researchers throughout the collection, analyses and interpretation of the data, to ensure that the data were presented in an accurate and truthful manner. Consultation amongst the researchers further prevented personal beliefs, values and experiences from influencing the interpretations formed and the findings derived from the study (Creswell, 2014). Finally, the first author took on the role of report writer, by writing up the findings, in consultation with the experienced research team.

\section{Research participants and sampling methods}

The target population of the study included full-time academics on a permanent employment contract, in various career stages, together with academic leaders employed at the university, during the 2020 academic year. Research identifies three main successive stages of an academic career trajectory (Christophersen, 2017), namely an early career stage, a midcareer stage and an advanced career stage. In addition to the core academic activities of research, teaching and community engagement, academics are also encouraged to take on leadership roles, especially in their mid- and established career stages. Whilst formal academic leadership roles such as a Head of Department, Chairperson or Deputy Dean positions are regarded as added responsibilities to the core academic activities, academic leadership roles could also take on the form of a detached position that primarily forms part of the senior 
institutional management team, with a distinct strategic set of key performance areas and deliverables ([location masked for blind review], 2009). Such academic leader roles include the positions of Deans, which formed part of the study population, and were included in the sampling of the study. Academics from the Dentistry faculty were not included, as they hold a dual employment contract with the respective university, and the National Department of Health, which implied that additional employment processes and career progression practices had to be considered. The study population further excluded academics employed on a fixed term contract.

A purposive sampling technique was used to recruit the participants for this study. Sandelowski (1995) proposed that an adequate sample size in qualitative research is one that permits the deep, case-oriented analysis, which is a hallmark of all qualitative inquiry, and results in a new and richly textured understanding of the experience. A total of 17 academics, across five of the faculties, in various academic career stages, participated in this study (Table 1).

\section{Data collection methods}

Semi-structured interviews were identified as an appropriate data collection method for the qualitative research design of this study, to address the research question. The semi-structured interview method is suitable for the studying of the participants' perceptions, experiences and opinions, regarding a particular context (Barriball \& While, 1994). The exploratory nature of the research study allowed the use of an open-ended interview guide, to conduct the semi-structured interviews with the participants. This allowed the same open-ended questions to be posed to all the participants, whilst still allowing them to expand and elaborate on their responses. It further allowed probing for further understanding and clarity, whilst remaining on track to investigate the objectives of the study. All the interviews were conducted virtually, through an online platform, and audiorecorded. This method of data collection was used because of the challenges of the COVID-19 pandemic, at the time. The challenges of such an instrument were that it was timeconsuming, in the time required to conduct each individual interview as well as in the transcribing and coding of the data.

\section{Data recording}

The audio-tape-recorded data were transcribed verbatim, soon after the interviews were conducted. Subsequently, the full data set was analysed, by using thematic analysis, with the focus on the content of the text, and not the manner in which the participants responded to the questions. The aim of this was to identify, analyse and report on the patterns (themes) in the data set (Braun \& Clarke, 2006). A deductive modality was adopted in an attempt to categorise the themes within the theoretical framework of the STF.

\section{Strategies employed to ensure data quality and integrity}

The trustworthiness criteria of credibility, transferability, dependability and confirmability were considered to ensure the quality and integrity for the qualitative nature of the research study (Guba \& Lincoln, 1982).
Credibility refers to the confidence that could be placed in the truth of the research findings and whether the research findings represent plausible information and interpretation drawn from the participants' original data (Macnee \& McCabe, 2008). The first author established credibility through the consultation and scholarly guidance of the two experienced researchers, as a means of peer debriefing. Peer debriefing is described as an opportunity for researchers to test their growing insights, whilst being exposed to searching questions (Guba \& Lincoln, 1982). For this reason, an overview of background information, data collection methods and process, data management and transcriptions, together with the data analysis procedure, as well as the research findings, were discussed (Pitney \& Parker, 2009). In addition, the first author kept a journal throughout the research process to create an opportunity for reflexivity, thereby minimising researcher bias (Malterud, 2001).

Transferability refers to the degree to which the research methods and findings could be transferred to another research setting (Bitsch, 2005). The researchers, therefore, provided a comprehensive description of the research methodology and context, whilst purposively selecting the participants. Dependability refers to the stability of the findings over time (Bitsch, 2005), which could be achieved through an available audit trail for future researchers, including the raw data and interview notes (Guba \& Lincoln, 1982). Confirmability is described as the degree to which the results of an inquiry could be confirmed or corroborated by other researchers (Baxter \& Eyles, 1997). The audit trail also established the confirmability of the study (Tobin \& Begley, 2004). Finally, this study received ethical clearance from the Human and Social Sciences Ethics Committee at the research university (ref: HS19/6/41).

TABLE 1: Participants' demographic and career stages.

\begin{tabular}{|c|c|c|c|}
\hline $\begin{array}{l}\text { Participant } \\
\text { code }\end{array}$ & $\begin{array}{l}\text { Male/ } \\
\text { female }\end{array}$ & Race & Faculty \\
\hline \multicolumn{4}{|c|}{ Early career stage } \\
\hline E1 & Female & White & Education \\
\hline E2 & Male & Coloured* & Education \\
\hline E3 & Female & Coloured* & Economic and Management Science \\
\hline E4 & Male & Black & Science \\
\hline \multicolumn{4}{|c|}{ Mid-career stage } \\
\hline M1 & Male & White & Economic and Management Sciences \\
\hline M2 & Female & Black & Science \\
\hline M3 & Female & White & Education \\
\hline M4 & Female & Black & Arts and Humanities \\
\hline \multicolumn{4}{|c|}{ Advanced career stage } \\
\hline A1 & Male & Black & Science \\
\hline A2 & Female & White & Community and Health Science \\
\hline A3 & Male & Black & Arts \\
\hline A4 & Female & Coloured* & Arts \\
\hline \multicolumn{4}{|c|}{ Academic leader } \\
\hline AL1 & Male & Coloured* & Science \\
\hline AL2 & Female & Coloured* & Community Health Science \\
\hline AL3 & Female & Coloured* & Economic and Management Science \\
\hline AL4 & Male & Coloured* & Education \\
\hline AL5 & Female & Black & Education \\
\hline
\end{tabular}




\section{Data analysis}

Following the complete transcriptions of the interviews, the researchers engaged the data set for in-depth knowledge, as part of the first critical step of the thematic approach, followed during the data analysis phase (Clarke, Braun, \& Hayfield, 2015). Meaningful chunks of the data were identified as the units of analysis and added into a Microsoft Excel worksheet per question. The units of analysis included phrases, words or whole paragraphs, which were each assigned a code. An important step in analysing and organising qualitative data is the ability to systematically identify and assign codes, or labels, to express or infer information gathered during the study (Basit, 2003). Subsequently, these codes were ordered into potential themes, to generate a plausible thematic map, in line with the STF. All the themes were reviewed next by the researchers, by checking them in relation to the coded extracts of the entire data set (Clarke et al., 2015). A few changes were made, by splitting or combining certain themes, whilst refining the boundaries of each theme. A final check was completed by the researchers to conclude the reviewing of the themes.

As a follow-up step, the four categories and 21 themes were defined, and names were assigned to ensure the conceptual clarity of each theme as well as to provide a road map for the final step, namely the writing-up of the results to report on this study. During the writing up of the report, the first author weaved the analytical narrative together with data extracts to contextualise the results and strengthen the validity of the interpretations (Clarke et al., 2015).

\section{Reporting style}

The STF was used as a guide for the thematic map of the results and therefore populated and presented in a diagram. In addition, a narrative was provided to describe the themes within the various categories to enhance understanding and clarity of the data for the reader.

\section{Findings and discussion}

The findings emerged from the purpose of the study, namely to explore and describe the perceived career management challenges of academics, at individual and organisational levels of the respective university. The STF was used to structure the findings into four categories: (1) the individual level category, representing the intrapersonal system of the STF; (2) the departmental category; (3) the institutional category, representing the organisational level and social system of the SDF; and (4) the external category that represents the environmental-societal system of the SDF. These categories include several themes as derived from the identified codes (Table 2).

The following themes emerged within the four categories (see Figure 2).

\section{Category 1: Individual level}

Five themes were recognised within category 1, namely demographics, personality, work-life balance, holistic wellbeing and skills and competencies.
TABLE 2: Codes adopted to inform the themes.

\begin{tabular}{ll}
\hline Codes & Themes \\
\hline Category 1: Individual level & \\
- Woman/man & Demographics \\
- Age & \\
- Race & \\
- Personal and professional life & Work-life balance \\
- Health & Holistic well-being \\
- Emotions & \\
- Expectations & Personality \\
- Values & \\
- Responses or reactions & \\
- Training & Skills and competencies \\
- Experience & \\
Category 2: Departmental level & \\
- Workload & Workload allocation \\
- Time & \\
- Work allocations & \\
- Culture (department) &
\end{tabular}

- Dynamic and support

- Perceptions

- Career goals

- Career support

- Role

- Transition

- Number of staff

Category 3: Institutional level

- Mentorship

- Sabbatical

- Promotions policy

- Lack of integrated support

- Intervention

- Clear criteria and requirements

- Policies

- Systems

- Support

- Performance management

- Performance assessment

- Funds

- Relationships

- Juggling/balancing roles

- Conflict

- Role dynamics

- Attitudes

Career management support

Role transition

Resources: Staffing

Career management strategy

- Values

- Feelings

- Experiences

- Power dynamic

- Perceptions

- Institutional decisions

- Strategies

- Goals/objectives (institutional)

Category 4: External level

- Student increase

- DHET requirements

- Regulations

- Social culture

Policies, systems and support (other)

Performance review and feedback

Resources: Funding

Networks and interpersonal/peer support Role conflict

Institutional culture

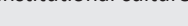

A diagram was then used to present the themes in the four categories.

Demographics: Women, in particular, perceived personal characteristics and social constructs, mainly their gender, race and age, as obstacles for the progression and management of their careers. Participant M4 shared 'it is challenging if you're a woman and you're an academic, a single mom, and you're trying to kind of make things happen'. This finding is aligned with extensive 


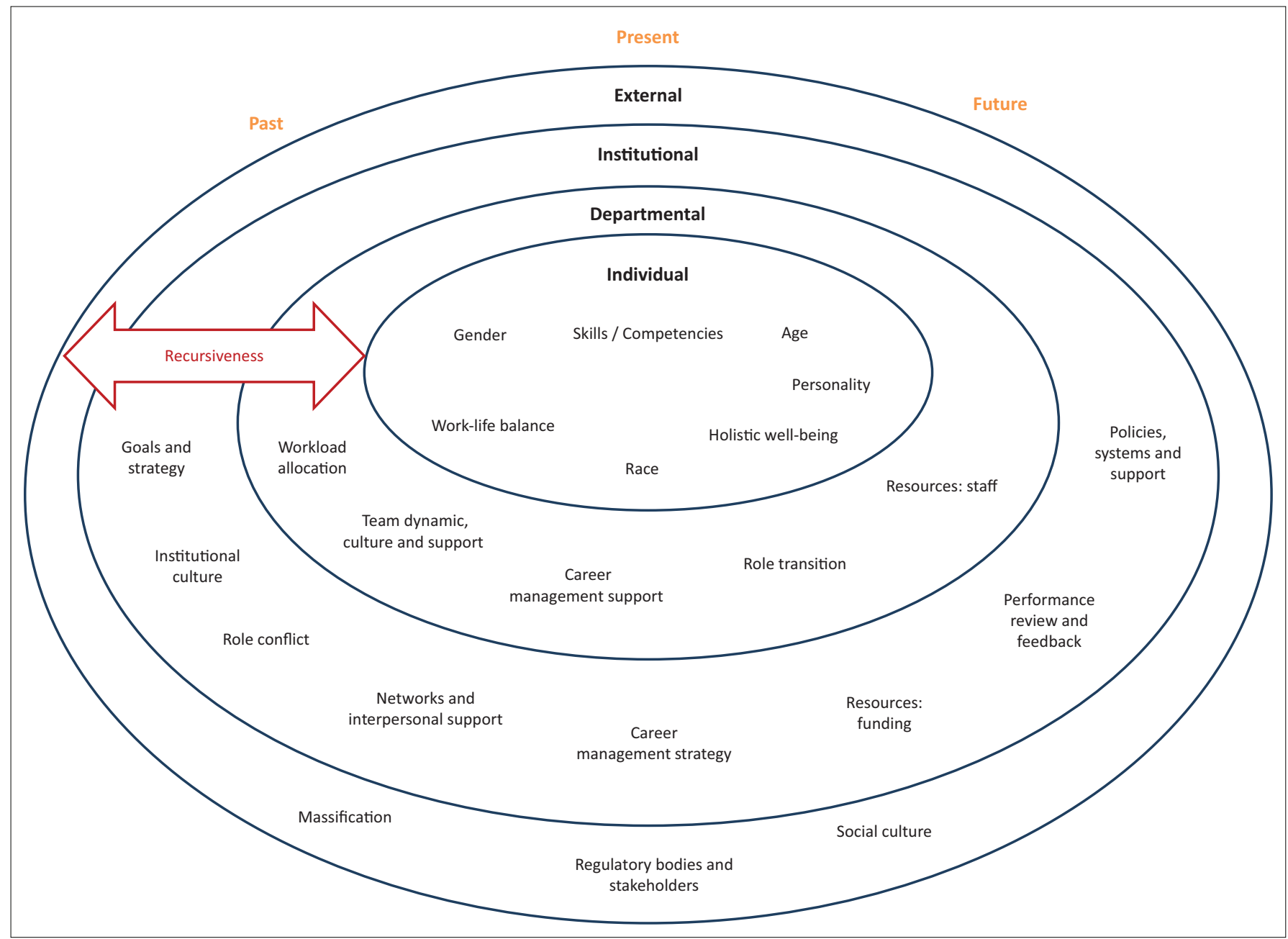

FIGURE 2: Findings structured into four themes as aligned to the systems-thinking framework.

research, to address the challenges for women in academia (Zacher et al., 2019). Simultaneously, the participants also highlighted the impact of their racial identities on their career, as participant AL4 expressed, 'the fact that I'm a woman and black influences my personal experiences and challenges', whilst another participant, E1, shared, 'as a white female, I am aware that all opportunities are not always available to me'. This finding reflects a key proposition of the social cognitive career theory in that individual identities contribute to the lived experiences, as they negotiate contextual influences (Lent, Brown, \& Hackett, 1994), and the experiences of women academics, with different racial identities, are not the same. In addition, this finding is further aligned with the negative association of age on career development opportunities (Van der Heijden, Schalk, Van Veldhoven, Van Veldhoven, \& Dorenbosch, 2008), as participant AL3 shared, 'at my age, people make assumptions and therefore it influences how they respond to me', whilst participant M3 said, 'I'm a late bloomer, in my 50s, there's nothing that you can apply for at this stage that will give you status as an established researcher'.

Personality: The participants identified characteristic sets of their thinking, feeling and behavioural patterns, which evolved from their biological and environmental factors, as a challenge from a personal perspective.

They highlighted the need for the individual and the work environment to be mutually responsive (Schreuder \& Coetzee, 2016), as participant AL3 expressed, 'I have certain expectations of others and can become frustrated with others if I feel there's no cooperation'. Participant E3 added, 'you must be development hungry to make a success'. This highlights a leading career development theory, the personenvironment theory, which identifies personality as a fundamental construct for successful career management (Patton, McMahon, \& Watson, 2006). However, research on the role of individual characteristics, other than gender, as well as personal resources for academic career development, is still relatively rare (Zacher et al., 2019).

Work-life balance: The participants experienced problems with the ability to maintain a reasonable balance between the time allocated for work and other aspects of their lives, especially their family responsibilities.

Participant M2 shared, 'juggling between family and a demanding workload, there's always a push for publication, but you can only do that after hours'. Simultaneously, they 
acknowledged that the nature of an academic career was not restricted to traditional working hours. Participants E4 expressed:

'I know academia is not the standard nine-to-five job, and there are many other professions that require working after hours; I would never finish with everything if I didn't work weekends.' (early career, female)

This finding confirms that people, increasingly, do not compartmentalise their lives and personal activities, but instead seek balance and integration throughout the lifespan (Schreuder \& Coetzee, 2016).

Holistic well-being: Emotional strain, because of a pressured environment, was identified as a challenge to the managing of their careers. Participant AL4 shared, 'it can be very lonely building an academic career; there's lot of pressure and my emotional well-being is very important'. Another, participant A3, raised concern about overall physical health as, 'I am afraid of the adverse impact on my health', as he believes 'many people who are prolific, well, they don't sleep'. This finding confirms the correlation between holistic employee well-being, and individual output and performance, with a subsequent impact on individual career development (Warr \& Nielsen, 2018).

Skills and competencies: The lack of administrator and management experience, knowledge and skills was identified by participants as a difficulty in the management of their academic careers. Participant M4 said, 'recognising that as an academic, I have not been taught to manage anything', whilst participant A4 expressed:

$[T]$ here is a mistaken view all over the world that because you are a professor, a senior academic, you should automatically be able to manage a department or a faculty. (advanced career, female)

It is evident that the career development and trajectory of an individual is highly dependent on mastering a set of skills, knowledge and the competencies required for a respective role (Greenhaus et al., 2010).

\section{Category 2: Departmental level}

In category 2, five themes related to experiences in their immediate work environment were identified, namely workload and allocation; team culture, dynamic and support; career management and support; role transitioning; and resources: staffing.

Workload allocation: Participants across all career phases experienced the amount of committee work and administrative duties, together with the marking of scripts, as an obstacle for the efficient management of their careers. An early career academic, participant E3, was concerned about, 'when will I find time to get my research going with my teaching load and all the administrative responsibilities that go with it?'. In addition, they were of the opinion that the work allocation had an adverse effect on their career progression, as participant M1, in a mid-career phase, indicated:

'[W]ork is divided to create "fairness" - the same teaching and community service is allocated across, and not according to career stage, or skill and expertise, and therefore puts my progress at a disadvantage.' (mid-career, male)

Participant A3, in an advanced career phase, raised that:

'[Y]ou need to look at opportunity costs when senior academics are bombarded with mundane admin - what are you losing by having them do something they were not equipped to do?' (advanced career, male)

Whilst the participants focussed on the potential implications of workload allocations, this finding is observed to be a typical challenge in academic career literature (Gregory \& Lodge, 2015).

Team dynamic, culture and support: The participants experienced the level of support they receive from colleagues in departments, together with the unconscious and underlying psychological forces that influenced the way they interacted and communicated with each other, to have an impact on their career management and progression. Participant AL5 shared:

'[T]he circumstances or conditions in the faculty - the support that you either get to stand or maybe continue your leadership role; or it could be that you are not popular enough.' (academic leader, female)

Participant M3 added that, 'an open and flexible culture is needed in the department'. This finding is aligned to the situational or sociological career theory that argues the proximal contextual environment - in this case, the team support and context-influenced individual career behaviours and outcomes (Lent et al., 1994).

Career management and support: The participants experienced a disparity between their career trajectory and the expectations of their performance objectives or deliverables, in relation to their individual strengths and competencies, at departmental level. In their view, their performance objectives and deliverables did not allow for their individual strengths and career competencies. Participant M1 indicated:

' $[P]$ erformance objectives and career goals are not structured around individual needs or strengths. Individual strengths are also not used to the benefit of others - e.g. as a more experienced researcher, I could support an emerging researcher.' (mid-career, male)

This finding is aligned with the view that active career decision-making is facilitated by an individual's reflection on his or her strengths, passions and values, in relation to his or her work (Lieff, 2009). In addition, academics are required to define clear goals, carefully negotiate their employment terms and use time management strategies to optimise their chances of success (Applegate \& Williams, 1990), as expressed by 
participant AL5 that, 'there is a sense of investment in your leadership role, but no guarantee that you will be able to further pursue it'.

Role transition: The move into, and back, from leadership roles were identified by more senior academics, as a challenge for career development, as it required an adjustment to a different set of competencies, expectations, responsibilities and positional power. Participant AL4 mentioned, 'transitioning into a leader or committee role and back can be difficult - to be part of decision-making and go back to not being part of decision-making'. This finding demonstrates that whilst challenges and typical support mechanisms, such as orientation programmes, are identified for new employees, during their transition into the organisation, challenges around intra-role transitioning (when an individual changes orientation to a role across all phases) should be considered (Greenhaus et al., 2010) as a key proposition of the life-span theory.

Resources and staffing: The participants viewed insufficient staff resources in departments as an obstacle for their careers. In their view, an inadequate number of staff members, in relation to the departmental objectives and deliverables, added pressure on them, and in turn, their career goals and objectives. Participant A4 said, 'our load has increased, but not the number of people that we employ', whilst participant E3 concurred with:

'I was not supposed to teach one semester according to my development plan, but my HOD came to me and asked me to help out. So the department's goals and staffing pressures put pressure on me.' (early career, female)

Whilst research on the role of work resources in academic career development is limited, Zacher et al. (2019) argue that there are several factors, including institutional resources and support, which could serve as contextual affordances, to either promote or hinder academic career development.

\section{Category 3: Institutional level}

In category 3, eight themes were identified that relate to their broader experiences at institutional level, including career management strategy; policies, systems and support; performance review and feedback; resourcing - funding; networks and interpersonal/peer support; role conflict; culture; and goals and strategies.

Career management strategy: The participants raised concern about various challenges related to a career management strategy. Whilst they acknowledged the broad guidelines available for academic promotions, they considered the absence of a policy and clear criteria for promotion of each career phase, as an obstacle in the managing of their careers. Participant M1 stated that, 'there are broad guidelines for promotion available, but not details or clear criteria; and it can be demotivating if you are not sure how to move forward'. An early career academic, participant E4, further disclosed, 'I need to understand the "mechanics" of developing as an academic'. This challenge is supported by the argument that a failure to apply promotion policies in higher education institutions, consistently, could lead to the deterioration of the professoriate (Bitzer, 2008).

In addition, the matter of sabbatical leave was raised as a related policy concern, with participant A1 stating that, 'it is problematic and slows down my progress if I can't apply for sabbatical in the first five years of employment'. Participant A4 added that, 'I haven't had a sabbatical in ten years, and I don't think I will be able to get one before I retire'. This finding is aligned with literature that regard sabbatical leave as an important process in the production and exchange of scientific knowledge, as well as the subsequent positive impact on the academic career (Zahir \& Fakhri, 2011).

A further challenge, identified by the participants, was the lack of integrated support in all career phases, with formal coordination of collaboration and partnerships. Participant M3, in a mid-career stage, shared that, 'there's no formal coordination of collaboration and partnerships; there's a need for integrated support that is sensitive to the rhythms of the academic year'. However, participant A1, in an advanced career stage, expressed the opinion that, 'when you are a senior academic, everyone expects you to know what you do, so all the interventions are targeted at early career academics'. This finding is aligned with academic career literature that indicates a limited development focus on the mid- and late-career stages of academics, with career development strategies predominantly focussed on early career academics (Zacher et al., 2019). The overall finding is supported by literature that advocate a strategic career management approach, which requires the systemic consideration, alignment and integration of career management practices, tools and interventions, with the overall strategy, policy and practices of an organisation (Schreuder \& Coetzee, 2016).

Policies, systems and support: Institutional policies, systems and support, with a specific focus on Procurement and Human Resources, were identified by the participants as an obstacle in the development of their careers. Participant AL3 disclosed that, 'support from all partners are needed and there should be clarity around HR and finance processes'. This statement was echoed by others, particularly those who were part of the established and leadership cohort. Participant A1 elaborated by providing an example of the impact on research projects by sharing:

'I understand that we must account and there must be procurement and HR structures in place, but it can also delay a big project. Example, a project was delayed for six months because someone did not sign - now at the end I also need to account at NRF.' (advanced career, male) 


\section{Participant A2 added:}

'[T]here are so many administrative burdens and demands that actually put pressure on projects and research to continue. Example, appointing field workers for my projects can be very challenging because of the admin/HR/finance requirements.' (advanced career, female)

Literature highlights the importance of considering employees' perceptions of policies and practices, as well as the influence thereof on employee behaviours and outcomes (Mey, Werner, \& Theron, 2014). Whilst the findings of this study represent challenges across all career phases, it is important to note that this respective finding was only identified by academics in an advanced and academic leader phase.

Performance review and feedback: A need for the review and feedback of clear performance expectations and indicators, as aligned to individual, departmental, as well as institutional strategies and goals, were highlighted by the participants as a challenge in managing their careers. Participant E3 shared, 'not knowing what is expected can be challenging; performance outcomes are not structured with clear goals'. Participant A3 added:

' $[W]$ hen you are being assessed, it's not how many committee meetings you attended or if you represented your HOD, but it's how many papers or how many books have you published.' (advanced career, male)

Whilst this finding is supported by the view that inadequate performance management is a typical career management obstacle in higher education (Miller, 2003), it also highlights the importance of general performance feedback as the preceding step and prerequisite for a development plan or career management process (Bussin, 2013). Although performance review and feedback forms part of a broader performance management system, known for its controversial views in higher education (Parsons \& Slabbert, 2001), it is essentially described as a management tool to ensure that the organisation meets its overall objectives (Bussin, 2013).

Resourcing and funding: The participants perceived their access to funds, especially the applied formulas and the time involved to establish an author's fund, as an obstacle for the efficient management of their careers. Participant E1 mentioned, 'if we look at the amount of time it takes to get published and to build up an author's fund', whilst participant E1 added, 'the formula used for supporting funds might be bit unfair'. The ability to acquire funding sources is found to be a prerequisite to a successful academic career (Gail Neely, Smith, Graboyes, Paniello, \& Paul Gubbels, 2016).

Networks and interpersonal/peer support: The opportunity to build authentic collaborative relationships with peers that could also provide a level of interpersonal support was perceived as a career management challenge by the participants. Participant M1 shared, 'the career can be very lonely and trying to build a reputation can be very lonely', whilst participant M3 said, 'we need time and space in our working calendar to build authentic collaborative relationships'. Literature confirms that supportive peer relationships could be instrumental in the support of career advancement, as well as personal growth (Kram \& Isabella, 1985).

Role conflict: The participants highlighted the competing demands of their role as researchers, with the management and administrative expectations, particularly their leadership roles. They experienced the balancing of their roles and responsibilities as a challenge to the management of their careers, as participant A1 indicated, 'wearing two hats at the same time is a challenge'. Participant AL5 feared, 'losing my academic profile when juggling between it with my administrator role', whilst participant AL4 added that, 'the dynamic between academic leader and reporting lines can be challenging'. Participant AL1 elaborated that:

' $[H]$ aving to give $100 \%$ to both roles, established researcher and academic, while my performance is measured on me giving $100 \%$ to both, but I can't give $100 \%$; you have to find that balance.' (academic leader, male)

Role conflict is regarded as another typical career obstacle that was identified in academic career literature (Miller, 2003).

Culture: Various aspects within the institutional culture were identified by the participants as obstacles to the managing of their academic careers. These include transitioning into their roles in academia, together with the pressures and politics thereof, as expressed by participant E2 as, 'I need to understand how I fit in, and also the academic pressures and the politics'. Communication and decision-making approaches, across the institution, was further identified as an obstacle. Participant E2 said, 'there are different discussions at different levels, and it is important that younger academics take part in these conversations to understand the bigger picture'. Participants further experienced the culture as individualistic and competitive, which they deemed similar to being under a microscope, with a lack of collaboration that is underpinned by values of care. Participant M3 said:

' $[A]$ collaborative culture underpinned by values and care is hard in academia, because there's a lot of competition; people are not prepared to co-supervise if people are not departmental colleagues, it's kind of territorial.' (mid-career, female)

Participant M3 added, 'it feels like you're under the microscope and academic work and thinking isn' $t^{\prime}$. Inclusion and trust from all partners, and in particular their reporting lines, were viewed as an obstacle in the managing of their careers, as participant AL4 shared, 'in my experience the voices of my white male peers are heard even if we are talking the same thing, while my voice is not'. The participants further highlighted that the gender dynamic was not only experienced between male and female identities, but a power dynamic existed, particularly amongst women. Participant AL3 said, 'prejudices exist between women too and not only just between men and women'. The overall finding regarding culture is supported by the view that a conducive culture for 
career development, as well as the growth of new and experienced academics, should be cultivated (PithouseMorgan et al., 2016).

Goals and strategies: The participants perceived that some institutional decisions of senior management were supposedly taken in the best interest of the students, without considering the operationalisation of such decisions or their impact on academic career development. Participant E3 shared:

'[A]s a student-centred institution, I feel top management make decisions in the best interest of the student, not taking into consideration how it will affect the rest of the institution or how we need to implement and make it happen.' (early career, female)

The participants further experienced some institutional goals and strategies as challenges with a potential limiting impact on their research, as participant M4 said:

'[S]ometimes you feel like you put in a box, because of institutional systems and processes; you obligated to respond in a particular way; although we need to align ourselves with the institutional vision, we shouldn't be limited to it.' (mid-career, female)

This finding is aligned to the social cognitive theory that organisational goals may either promote, or hinder, academic career development (Zacher et al., 2019).

\section{Category 4: External level}

Finally, category 4 revealed three themes, namely massification, regulatory bodies and stakeholders, as well as social culture.

Massification: This is described as the massive increase of enrolment in higher education as the social and economic demand for qualifications increases (CHE, 2016). Participants identified the need for faculty and overall institutional objectives to 'increase the student numbers' (Participant A4), as a direct impact on their workload and career management. Globally, massification has resulted in significant pressure on academic staff members (CHE, 2016).

Regulatory bodies and stakeholders: The expectations and reporting requirements of external regulatory bodies, including the national Department of Higher Education and Training (DHET), were identified as a challenge for the career development of academics. Participant AL2 said, 'we have to consider external requirements and expectations beyond the university, such as the Health Professions Council of South Africa (HPCSA) and reporting to DHET; having to navigate through that can be challenging'. Maguad (2018) confirms the need for higher education institutions to consider the interdependency, as well as impact of systems and structures that are external to the university.

Social culture: Adapting to the social culture in which the institution is located has been identified by transnational scholars as a challenge for their career management, as participant M4 said, 'adapting to the culture outside the university, as a transnational scholar, is not easy, especially without a support structure'. Whilst the difficulties of cross-cultural adjustment have been studied, little research has considered the process of academic career development, from a cross-national perspective (Zacher et al., 2019).

In addition to the given themes that emerged in each of the four categories, it is also important to note a central construct of the STF, namely recursiveness, which acknowledges the inseparability of parts from the whole; therefore, it is essential to think of these categories as integrated and dynamic (Vondracek et al., 2014). This was captured by participant A3 who stated the following:

'I don't think it's easy to compartmentalise my personal challenges from my environmental obstacles. There is a dynamic interface between personal and systemic challenges. My personnel challenges or opportunities and successes are a function of the environment in which I find myself professionally. Can't divorce my personal challenges from the framework or conditions I have at my workplace.' (advanced career, male)

The overall findings are aligned to career development literature in two ways. Firstly, it aligns with the typical academic career challenges identified, with the exception of one challenge. Poor remuneration (Koen, 2006) was not perceived as a career challenge by the participants of this study. Secondly, in this study, the authors identified several additional perceived career challenges for academics, which are supported by general career literature and theory.

\section{Practical implications}

Whilst literature identifies typical career management challenges of academics, a number of additional challenges were identified in this study, through an integrated approach, as experienced by academics, in all career phases, at the respective university. The findings provide an unambiguous understanding of the career management challenges, as perceived by the academics in all career phases, for the purpose of strategy and intervention development.

This research contributes to the existing knowledge of the career obstacles of academics, together with the current scholarly debate of higher education, as a critical juncture of integrated complexity and context (Waller et al., 2019). In addition, the findings of this study provide leaders and talent management practitioners in the higher education sector with the components to consider, through a systems-thinking approach, when negotiating the landscape for academic career success.

\section{Limitations and recommendations}

Whilst the main disadvantage of a qualitative approach is that the findings cannot be extended to the broader research population (Creswell, 1994), in this study the researchers 
explored the perceived challenges of academics, whilst acknowledging the complexity and context of the respective university.

The findings, however, could provide leaders and talent management practitioners in the higher education sector with the components to consider, through a systemsthinking approach, when reproducing contextually sensitive maps and negotiating the landscape for academic career success.

\section{Conclusion}

The findings of this study identified typical career management challenges in academic career literature and additionally confirmed a number of additional obstacles for academics in a systems framework. Consequently, the findings of this study allow leaders and talent management practitioners in the higher education sector to consider the components, through a systems-thinking approach, when negotiating the landscape for academic career success.

\section{Acknowledgements Competing interests}

The authors declare that they have no financial or personal relationship(s) that may have inappropriately influenced them in writing this article.

\section{Authors' contributions}

All authors made substantial contribution to the conception and design of the study, together with the analysis and interpretation of the data. Whilst N.B. drafted the manuscript, M.D.P. and J.F. critically revised it for important content. All authors approved the final version for submission of the manuscript.

\section{Funding information}

The research was financially supported by the Academic Doctorate Advancement Programme Towards Transformation (ADAPTT).

\section{Ethical considerations}

The study received ethical clearance from the Human and Social Sciences Ethics Committee at the University of the Western Cape.

\section{Data availability}

The data that support the findings of this study are available from the corresponding author upon reasonable request.

\section{Disclaimer}

The views and opinions expressed in this article are those of the authors and do not reflect the official policy or position of any affiliated agency of the authors.

\section{References}

Applegate, W.B., \& Williams, M.E. (1990). Career development in academic medicine The American Journal of Medicine, 88(3), 263-267. https://doi.org/10.1016/00029343(90)90152-4

Ball, D. (2004, October 18). Attracting the right staff is a mission. Sunday Business Times, Johannesburg, p. 22

Barriball, K.L., \& While, A. (1994). Collecting da.ta using a semi-structured interview: A discussion paper. Journal of Advanced Nursing-Institutional Subscription, 19(2) 328-335. https://doi.org/10.1111/j.1365-2648.1994.tb01088.x

Baruch, Y., \& Hall, D.T. (2004). The academic career: A model for future careers in other sectors. Journal of Vocational Behavior, 64(2), 241-262. https://doi. org/10.1016/j.jvb.2002.11.002

Baruch, Y., \& Peiperl, M. (2000). Career management practices: An empirical survey and implications. Human Resource Management, 39(4), 347-366. https://doi. org/10.1002/1099-050X(200024)39:4\%3C347::AID-HRM6\%3E3.0.CO;2-C

Baruch, Y., Szúcs, N., \& Gunz, H. (2015). Career studies in search of theory: The rise and rise of concepts. Career Development International, 20(1), 3-20. https://doi. org/10.1108/CDI-11-2013-0137

Basit, T. (2003). Manual or electronic? The role of coding in qualitative data analysis. Educational Research, 45(2), 143-154.

Baxter, J., \& Eyles, J. (1997). Evaluating qualitative research in social geography: establishing 'rigour' in interview analysis. Transactions of the Institute of British

Bitsch, V. (2005). Qualitative research: A grounded theory example and evaluation criteria. Journal of Agribusiness, 23(1), 75-91.

Bitzer, E.M. (2008). The professoriate in South Africa: Potentially risking status inflation. South African Journal of Higher Education, 22(2), 265-281. https://doi. org/10.4314/sajhe.v22i2.25785

Blustein, D. (2013). The psychology of working: A new perspective for career development, counseling, and public policy. London: Routledge.

Braun, V., \& Clarke, V. (2006). Using thematic analysis in psychology. Qualitative Research in Psychology, 3(2), 77-101. https://doi. org/10.1191/1478088706qp063oa

Bussin, M. (2013). Performance management for government, universities, schools and NGOs: A practical and informative textbook for managing performance in service delivery-orientated organisations. Gauteng: Knowres Publishing, Randburg.

Callaghan, C.W. (2015). Designation differences and academic career progression. Acta Commercii, 15(1), 1-12. https://doi.org/10.4102/ac.v15i1.267

Caplow, T., \& McGee, R.J. (2001). The academic marketplace (rev. edn.). New Brunswick, NJ: Transaction Publishers.

Christophersen, E.R. (2017). Career development and promotion in an academic health center. Journal of Clinical Psychology in Medical Settings, 24(1), 41-46. https://doi.org/10.1007/s10880-017-9488-9

Clarke, V., Braun, V., \& Hayfield, N. (2015). Thematic analysis. In J.A. Smith (Ed.), Qualitative psychology: A practical guide to research methods (pp. 222-248). London: Sage.

Council on Higher Education [CHE]. (2016). South African higher education reviewed: Two decades of democracy. Pretoria: CHE. Retrieved from https://www. researchgate.net/publication/312889357 South_African_Higher_Education researchgate.net/publication/312889357_South_African_Higher_Education
Reviewed_Two_decades_of_Democracy_including_chapter_on_Governance

Creswell, J.W. (1994). Research design: Qualitative \& quantitative approaches. Thousand Oaks, CA: Sage.

Creswell, J.W. (2014). A concise introduction to mixed methods research. Los Angeles, CA: Sage.

De Vos, A., \& Cambré, B. (2017). Career management in high-performing organizations: A set-theoretic approach. Human Resource Management, 56(3), 501-518. https://doi.org/10.1002/hrm.21786

Gail Neely, J., Smith, R.J., Graboyes, E.M., Paniello, R.C., \& Paul Gubbels, S. (2016) Guide to academic research career development. Laryngoscope Investigative Otolaryngology, 1(1), 19-24. https://doi.org/10.1002/lio2.5

Gothard, B., Mignot, P., Offer, M., \& Ruff, M. (2001). Careers guidance in context. London: Sage.

Greenhaus, J.H., Callanan, G.A., \& Godshalk, V.M. (2010). Career management Thousand Oaks, CA: Sage.

Gregory, M.S.J., \& Lodge, J.M. (2015). Academic workload: The silent barrier to the implementation of technology-enhanced learning strategies in higher education Distance Education, 36(2), 210-230. https://doi.org/10.1080/01587919.2015.1055056

Guan, Y., Zhou, W., Ye, L., Jiang, P., \& Zhou, Y. (2015). Perceived organizational career management and career adaptability as predictors of success and turnover intention among Chinese employees. Journal of Vocational Behavior, $88(\mathrm{x})$, 230-237. https://doi.org/10.1016/j.jvb.2015.04.002

Guba, E.G., \& Lincoln, Y.S. (1982). Epistemological and methodological bases of naturalistic inquiry. Educational Communications and Technology Journal, 30(4), 233-252.

Koen, C. (2006). Higher education and work: Setting a new research agenda. Cape Town: Human Sciences Research Council (HSRC) Press.

Korsakova, T.V. (2019). Higher education in VUCA world: New metaphor of university European Journal of Interdisciplinary Studies, 5(2), 31-35. https://doi. org/10.26417/ejis.v5i2.p31-35

Kram, K.E., \& Isabella, L.A. (1985). Mentoring alternatives: The role of peer relationships in career development. Academy of Management Journal, 28(1), 110-132. https://doi.org/10.5465/256064 
Lent, R.W., Brown, S.D., \& Hackett, G. (1994). Toward a unifying social cognitive theory of career and academic interest, choice, and performance. Journal of Vocational Behavior, 45(1), 79-122. https://doi.org/10.1006/jvbe.1994.1027

Leong, F.T., \& Hartung, P.J. (2000). Cross-cultural career assessment: Review and prospects for the new millennium. Journal of Career Assessment, 8(4), 391-401. https://doi.org/10.1177/106907270000800408

Lieff, S.J. (2009). Perspective: The missing link in academic career planning and development: Pursuit of meaningful and aligned work. Academic Medicine, 84(10), 1383-1388. https://doi.org/10.1097/ACM.0b013e3181b6bd54

Macnee, C.L., \& McCabe, S. (2008). Understanding nursing research: Using research in evidence-based practice. Philadelphia, PA: Lippincott Williams \& Wilkins.

Maguad, B.A. (2018). Managing the system of higher education: Competition or collaboration? Education, 138(3), 229-238.

Malterud, K. (2001). Qualitative research: Standards, challenges, and guidelines. The Lancet, 358(9280), 483-488. https://doi.org/10.1016/S0140-6736(01)05627-6

McMahon, M., \& Patton, W. (2018). Systemic thinking in career development theory: Contributions of the systems theory framework. British Journal of Guidance Counselling, 46(2), 229-240. https://doi.org/10.1080/03069885.2018.1428941

McMahon, M.L., \& Watson, M.B. (2008). Systemic influences on career development: Assisting clients to tell their career stories. The Career Development Quarterly, 56(3), 280-288. https://doi.org/10.1002/j.2161-0045.2008.tb00043.x

Mey, M., Werner, A., \& Theron, A. (2014). The influence of perceptions of organizational trust and fairness on employee citizenship. Problems and Perspectives in Management, 12(3), 99-105.

Miller, K. (2003). Values, attitudes, and job satisfaction. In S.P. Robbins, A. Odendaal, \& G. Roodt (Eds.), Organisational behaviour - Global and South African perspectives (pp. 65-82). Cape Town: Pearson Education.

Monnapula-Mapesela, L. (2002). Staff satisfaction in a South African university undergoing transformation. Unpublished doctoral dissertation. Bloemfontein University of the Free State. Retrieved from https://scholar.ufs.ac.za/xmlui/ handle/11660/6307

Munhall, P.L. (2001). Ethical considerations in qualitative research. In P. Munhall (Ed.) Nursing research: A qualitative perspective (pp. 537-549). Sudbury, MA: Jones \& Bartlett

Nelson, D.L., \& Burke, R.J. (2000). Women executives: Health, stress, and success Academy of Management Executive, 14(2), 107-121. https://doi.org/10.5465/ ame.2000.3819310

Parsons, P.G., \& Slabbert, A.D. (2001). Performance management and academic workload in higher education. South African Journal of Higher Education, 15(3), 74-81. https://doi.org/10.4314/sajhe.v15i3.25328

Patton, W., \& McMahon, M. (1999). Career development and systems theory: A new relationship. Washington, DC: Thomson Brooks/Cole Publishing Co.

Patton, W., \& McMahon, M. (2014). Career development and systems theory: Connecting theory and practice (3rd edn.). Rotterdam: Sense.

Patton, W., McMahon, M., \& Watson, M.B. (2006). Career development and systems theory: Enhancing our understanding of career. In G. Stead, \& M.B. Watson (Eds.) Career psychology in the South African context (pp. 65-78). Pretoria: Van Schaik Publishers.

Pienaar, C., \& Bester, C. (2007). Mid-career problems of academics in higher education. Acta Academica, 39(3), 224-237.

Pithouse-Morgan, K., Naicker, I., Pillay, D., Masinga, L., \& Hlao, T. (2016). 'Sink or swim?': Learning from stories of becoming academics within a transforming university terrain. South African Journal of Higher Education, 30(1), 224-244. https://doi.org/10.20853/30-1-561
Pitney, W.A., \& Parker J. (2009). Qualitative research in physical activity and the health professions. Retrieved from http://ndl.ethernet.edu.et/handle/123456789/42900 Ragin, C.C. (2000). Fuzzy-set social science. Chicago, IL: Chicago University Press.

Republic of South Africa [RSA], \& National Planning Commission [NPC]. (2013) National Development Plan - 2030 our-future-make-it-work. Retrieved from https://www.nationalplanningcommission.org.za/National_Development_Plan

Sandelowski, M. (1995). Sample size in qualitative research. Research in Nursing and Health, 18(2), 179-183. https://doi.org/10.1002/nur.4770180211

Schreuder, A.M.G., \& Coetzee, M. (2016). Careers: An organisational perspective (5th edn.). Cape Town: Juta.

Segers, J., \& Inceoglu, I. (2012). Exploring supportive and developmental career management through business strategies and coaching. Human Resource Management, 51(1), 99-120. https://doi.org/10.1002/hrm.20432

Strike, T., \& Taylor, J. (2009). The career perceptions of academic staff and human resource discourses in English higher education. Higher Education Quarterly, 63(2), 177-195. https://doi.org/10.1111/j.1468-2273.2008.00404.x

Szelągowska-Rudzka, K. (2018). Human resources management in higher education institutions in Poland. Management, 22(1), 208-225. https://doi.org/10.2478/ manment-2018-0015

Tobin, G.A., \& Begley, C.M. (2004). Methodological rigour within a qualitative framework. Journal of Advanced Nursing, 48(4), 388-396. https://doi. org/10.1111/j.1365-2648.2004.03207.x

Tytherleigh, M.Y., Rothmann, S., \& Barkhuizen, N. (2008). Model of work-related ill health of academic staff in a South African higher education institution. South African Journal of Higher Education, 22(2), 404-422. https://doi.org/10.4314/ sajhe.v22i2.25794

University of the Western Cape (2009). Standing order: Academic role clarity. The researchers only have access to a hard copy, as the institution recently launched intranet; therefore, an electronic copy will be made available soon.

University of the Western Cape. (2013). University of the Western Cape history. Retrieved from https://www. uwc.ac.za/Pages/History.aspx

Van der Heijden, B., Schalk, R., Van Veldhoven, M.J., Van Veldhoven, M., \& Dorenbosch, L. (2008). Age, proactivity and career development. Career Development International, 13(2), 112-131. https://doi.org/10.1108/13620430810860530

Von Bertalanffy, L. (1967). General theory of systems: Application to psychology. Socia Science Information, 6(6), 125-136. https://doi.org/10.1177/053901846700600610

Vondracek, F.W., Ford, D.H., \& Porfeli, E.J. (2014). A living systems theory of vocational behavior and development. Rotterdam: Sense.

Waller, R.E., Lemoine, P.A. Mense, E.G., Garretson, C.J. \& Richardson, M.D. (2019). Global higher education in a VUCA world: Concerns and projections. Journal of Education and Development, 3(2), 73. https://doi.org/10.20849/ journal of Educ

Warr, P., \& Nielsen, K. (2018). Wellbeing and work performance. In E. Diener, S. Oishi, \& L. Tay (Eds.), Handbook of well-being (pp. 1-22). Salt Lake City, UT: DEF Publishers.

Watts, A.G., Hawthorn, R., Law, B., Killeen, J., \& Kidd, J.M. (1996). Rethinking careers education and guidance: Theory, policy and practice. London: Routledge.

Zacher, H., Rudolph, C.W., Todorovic, T., \& Ammann, D. (2019). Academic caree development: A review and research agenda. Journal of Vocational Behavior 110(Part B), 357-373. https://doi.org/10.1016/j.jvb.2018.08.006

Zahir, A.T.P., \& Fakhri, L.S. (2011). Improve faculty effectiveness by sabbatical leave Procedia-Social and Behavioral Sciences, 29, 917-926. https://doi.org/10.1016/ j.sbspro.2011.11.322 